\title{
Inhibitory Effect of Cancer Cells Proliferation from Epigallocatechin-3-O-gallate
}

\author{
Hyun Woo Kang* \\ Department of Korean Food \& Culinary Arts, Youngsan University, Busan, Korea \\ *Corresponding author: khw7200@ysu.ac.kr
}

Received March 17, 2015; Revised April 22, 2015; Accepted April 27, 2015

\begin{abstract}
Epigallocatechin-3-O-gallate (EGCG), the major polyphenol of green tea and a functional food ingredient/nutraceutical with health-promoting properties. However, its anti-cancer activities on various cancer cells are still little information. Here, we show that anti-cancer activities of the EGCG were evaluated using apoptosis assays analyzed by flow cytometry. The inhibitory activities of proliferation in MPC-11, Caco-2, and MCF-7 cells, values were $66.2,60.3$, and $74.8 \%$ at $10 \mu \mathrm{M}$, respectively. In addition, in an flow cytometry assay on the MPC-11, Caco-2, and MCF-7 cells, the EGCG showed a cell apoptosis effect on cancer/tomor in vitro model. Our results indicate that EGCG has anti-cancer activities against human lung cancer cells through inducing cell cycle arrest, DNA damage and activating mitochondrial signal pathway. These results indicate that EGCG effectively inhibits in vitro tumor growth by inducing apoptosis of cancer cells.
\end{abstract}

Keywords: EGCG, cancer/tumor, cell apoptosis, flow cytometer

Cite This Article: Hyun Woo Kang, "Inhibitory Effect of Cancer Cells Proliferation from Epigallocatechin3-O-gallate.” Journal of Food and Nutrition Research, vol. 3, no. 4 (2015): 281-284. doi: 10.12691/jfnr-3-4-8.

\section{Introduction}

Green tea is one of the most widely consumed beverages in the world and its probable health benefits have been the subject of considerable attention [1]. About three billion kilograms of tea is produced and consumed yearly [2]. Epigallocatechin-3-O-gallate (EGCG), the major bioactive polyphenolic compound in tea, has been known to possess anticancer, antioxidant, and antiinflammation activity [1,3]. Also, EGCG and other tea polyphenols have been shown to prevention/protective effect of various cancer or tumor of the skin, lung, oral cavity, esophagus, stomach, small intestine, colon, bladder, liver, pancreas, prostate and mammary glands [4,5,6]. In addition, EGCG is relatively safe [1,6], and green tea extract containing 60\% EGCG has been approved by the US Food and Drug Administration as the first botanical drug [7].

Apoptosis is a naturally occurring process of programmed cell death. In general, drug-induced apoptosis is a major reason for treatment of cancer, and some signal pathways are involved in the process [8]. The intensive efforts and substantial advances that have occurred through focusing on improving treatments, the efficacy of cancer therapies, especially for late-stage disease, remains poor overall, and cancer is still a leading cause of death worldwide [9]. Since the idea of cancer chemoprevention was introduced by Sporn [10] and Wattenberg et al., [11] the hope for overcoming cancer has started to change from one of treatment to one of prevention. The World Health Organization (WHO) indicates that one-third of all cancer deaths are preventable and that diet is closely linked to cancer prevention [12].

In this study, we investigated the effect of green tea polyphenol EGCG on various cancer cell lines.

\section{Materials and Methods}

\subsection{Materials}

EGCG, 3-[4,5-dimethy-thiazol-2-yl]-2,5-diphenyl tetrazolium bromide (MTT) assay kit were procured from Sigma Aldrich (St. Louis, MO, USA). Culture plates and culture dishes were purchased from Nunc, Inc. (North Aurora Road, IL, USA). Dulbecco's modified eagle’s medium (DMEM), Roswell Park Memorial Institute (RPMI), fetal bovine serum (FBS), penicillin, and streptomycin were purchased from Hyclone (Logan, UT, USA). All other reagents were of the highest grade available commercially.

\subsection{Cell Culture}

MPC-11, Caco-2, and MCF-7 cell line obtained from American Type Culture Collection (ATCC, Rockville, MD, USA), were cultured in DMEM and RPMI supplemented with penicillin, streptomycin and $10 \%$ heatinactivated $\mathrm{FBS}$ in $5 \% \mathrm{CO}_{2}, 95 \%$ air and humidified atmosphere at $37^{\circ} \mathrm{C}$.

\subsection{MTT Assay}

For evaluating the cytotoxicity of EGCG, the cells were harvested using phosphate buffered saline (PBS) 
containing $0.15 \%$ trypsin and $0.08 \%$ EDTA, Cells were incubated in well plates at a density of $5 \times 10^{5}$ cells/well. MTT solution was added to each well. Following incubation for $4 \mathrm{~h}$ at $37^{\circ} \mathrm{C}$ in $5 \% \mathrm{CO}_{2}$, the supernatant was removed. The medium was removed and the cells were washed by PBS twice, and the formazan crystals produced in viable cells were solubilized in $200 \mu \mathrm{L}$ DMSO. The absorbance was measured using a microplate reader (Tecan Trading AG, Männedorf, Switzerland) at $550 \mathrm{~nm}$. All experiments were performed with three replicates [13].

\subsection{Measurement of Cell Apoptosis}

For sub-G1 and cell cycle analysis, B16 cells were suspended in ethanol with $0.5 \%$ Tween-20 and left for 24 $\mathrm{h}$ at $4^{\circ} \mathrm{C}$. The cells were then harvested by centrifugation and resuspended in $1.0 \mathrm{~mL}$ of phosphate-buffered saline containing $0.05 \mathrm{mg} / \mathrm{mL}$ of PI and $10 \mu \mathrm{g} / \mathrm{mL}$ of RNase A, and incubated at $37^{\circ} \mathrm{C}$ for $30 \mathrm{~min}$. Analysis of apoptotic cell death was performed by measuring the hypodiploid DNA contents using a flow cytometer (FACS-Caliber; Becton Dickinson; Franklin Lakes, NJ, USA). The cells in the sub-G1 population were considered apoptotic cells, and the percentage of cells in each phase of the cell cycle was determined [14].

\subsection{Statistical Analysis}

Statistical analyses were performed 3 times for all the experiments. The data are expressed as the mean \pm one standard error of mean (SEM). Statistical analyses were assessed by Student's $t$-test for paired data. Graph Pad Prism software version 4.00 (Graph Pad Software Inc., San Diego, CA) was used. Significant differences ( $<<$ 0.05 ) between the mean values of the triplicate samples were determined for various assays.

\section{Results and Discussion}

The effect of EGCG that the viability of three kinds of cancer/tumor cells were examined by MTT assay. MPC11, Caco-2, and MCF-7 cells were treated with EGCG at various concentrations $(0,0.01,0.1,1.0,5.0$, and $10.0 \mu \mathrm{M}$, respectively) for $18 \mathrm{~h}$. As shown in Figure 1 (A, B, C), EGCG at up to $0.01 \mu \mathrm{M}$ showed cytostatic activity against MPC-11, Caco-2, and MCF-7 cells proliferation, and Caco-2 cells inhibitory effect was slightly better than that of MPC-11, and MCF-7. We further investigated the underlying basis of the proliferation-inhibiting effects of EGCG. Cell apoptosis analysis showed the distribution of apoptotic cells throughout the cell cycle, as shown in Figure 2 (A, B, C), where the percentage of apoptotic cells in non-treated cells was $7.49 \%$. The percentages of apoptotic cells in cultures treated with EGCG were 3.23, 4.41 , and $4.41 \%$, respectively. Cancers or/and tumors may be reduced by inhibiting cell growth or increasing apoptosis.

B

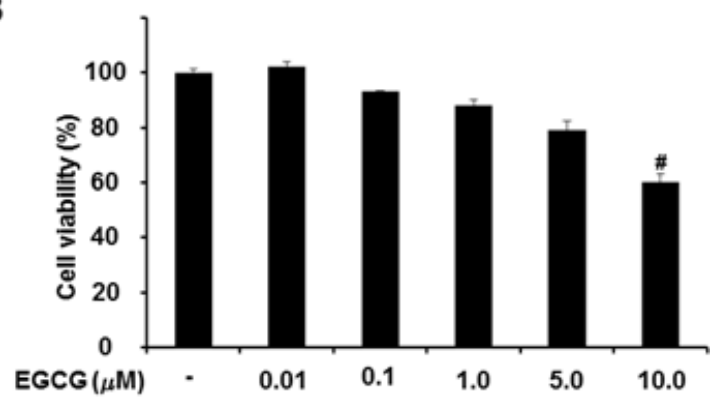

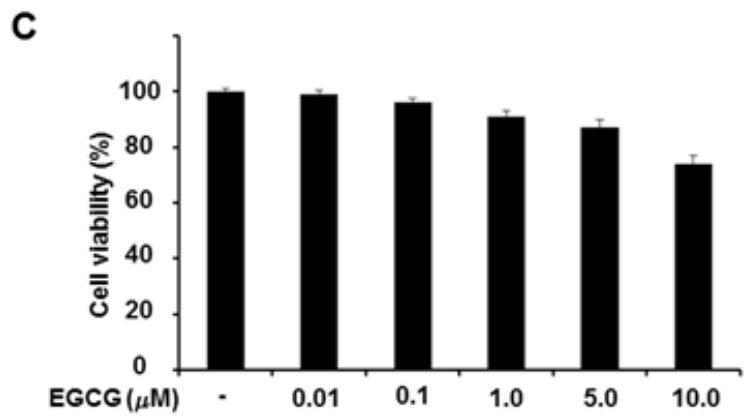

Figure 1. Effect of EGCG on the cell viability of MPC-11 (A), Caco-2 (B), and MCF-7 (C) cells using the MTT assay. various cells were incubated with $0.01,0.1,1,5$, and $10 \mu \mathrm{M}$ of EGCG for $18 \mathrm{~h}$. The results are shown as percentages of control samples. Data are presented as the mean \pm S.E.M. (n $=3$ ) for three independent experiments. Significance was determined by Student's $t$-test. $\# p<0.05$

The activity of tea and tea polyphenols on the inhibition of skin tumorigenesis has been widely studied. Early reported that the oral administration of green tea polyphenols (GTP) reduced UVB-induced skin tumor incidence, tumor multiplicity and tumor growth in SKH-1 mice [15]. There was also reduced expression of the matrix metalloproteinases (MMP)-2 and MMP-9, CD31, vascular endothelial growth factor (VEGF) and proliferating cell nuclear antigen in the GTP treated group.
Additionally, there were more cytotoxic CD8 (+) T cells and greater activation of caspase- 3 in the tumors of the orally administered GTP group indicating the apoptotic death of the tumor cells [15]. Recently, EGCG was found to suppress Wnt signaling in invasive breast cancer cells [16]. Green tea or EGCG exhibited chemopreventive action on 7,12-dimethylbenz[a]anthracene-induced mammary carcinogenesis only when given in the postinitiation stage, and the effect was not dose dependent. 
In additon, green tea ingestion markedly increased the mean latency of tumors and reduced the tumor burden and the number of invasive tumors in rats with 7,12dimethylbenz[a]anthracene induced mammary carcinogenesis [17]. In a case-control study conducted in China, drinking green tea was found to decrease the risk of esophageal and gastric cancers [18]. It has been reported that small intestinal tumorigenesis was inhibited in a dose-dependent manner by oral administration of EGCG which was accompanied by increased levels of Ecadherin and decreased levels of nuclear $\beta$-catenin, c-myc, phospho-Akt, and phospho-ERK1/2 in small intestinal tumors in Apc (min/+) mice [19,20].
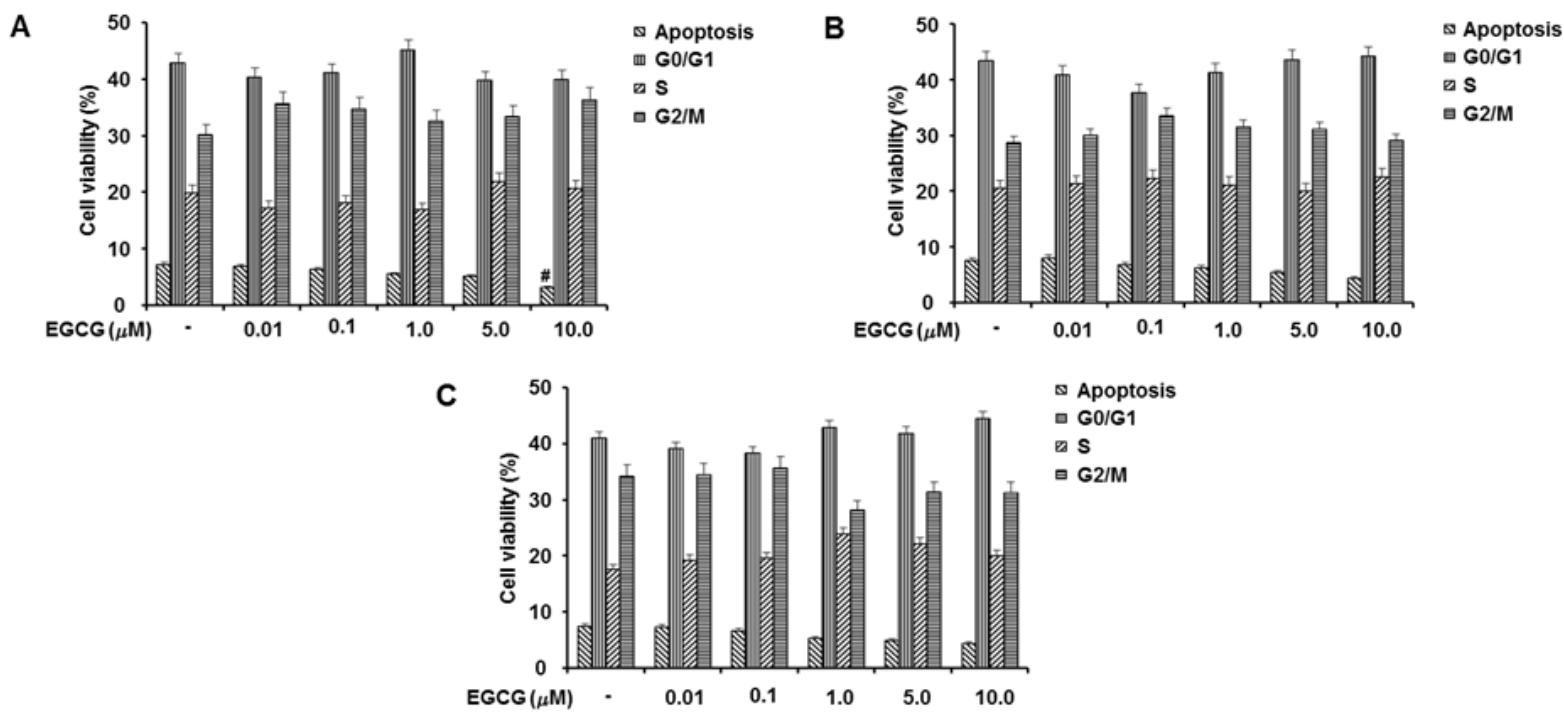

Figure 2. Cell death and cycle of MPC-11 (A), Caco-2 (B), and MCF-7 (C) cells using flow cytometry analysis. various cells were incubated with 0.01 , $0.1,1,5$, and $10 \mu \mathrm{M}$ of EGCG for $24 \mathrm{~h}$. The results are shown as percentages of control samples. Data are presented as the mean \pm S.E.M. $(\mathrm{n}=3$ ) for three independent experiments. Significance was determined by Student's $t$-test. $\# p<0.05$

High consumption of bioactive food compounds is inversely associated with the incidence and mortality rate of cancer. Many previous studies have shown that the food compounds inhibit cancer cell growth in vitro and in vivo, but only a little researches of EGCG on anticancer property were reported. In the present study, we showed that EGCG inhibitory effects in MPC-11, Caco-2, and MCF-7 cells. Furthermore, the regulatory effect of EGCG in molecular mechanisms of cancer in animal will be needed.

\section{Conclusions}

The current study demonstrated that green tea polyphenol EGCG has an inductive effect on various cancer cells. In light of the fact that natural products have been used as traditional medicines and now are potential sources of new drugs or nutraceuticals, our study to verify inhibitory effects of cancer cell from EGCG and its less toxicity and better tolerability, further consideration of the therapeutic applications.

\section{Acknowledgments} 2014.

This research was supported by Youngsan University in

\section{References}

[1] Lee, S.J., Kang, H.W., Lee, S.Y., and Hur, S.J., "Green tea polyphenol epigallocatechin-3-O-gallate attenuates lipopolysaccharide-induced nitric oxide production in RAW264.7 cells” J Food Nutr Res 2(7), 425-428. 2014
[2] MacMicking, J., Xie, Q.W., and Nathan, C., "Nitric oxide and macrophage function”, Annu Rev Immunol 15, 323-350. 1997.

[3] Schoedon, G., Schneemann, M., Walter, R., Blau, N., Hofer, S., and Schaffner, A., "Nitric oxide and infection: another view" Clin Infect Dis 21(Suppl 2), S152-157. 1995.

[4] Forman, H.J., and Torres, M., "Redox signaling in macrophages" Mol Aspects Med 22(4-5), 189-216. 2001.

[5] Kim, S., and Ponka, P., "Nitric oxide-mediated modulation of iron regulatory proteins: implication for cellular iron homeostasis" Blood Cells Mol Diseases 29(3), 400-410. 2002.

[6] Yang, C.S., Wang, X., Lu, G., and Picinich, S.C., "Cancer prevention by tea: animal studies, molecular mechanisms and human relevance” Nat Rev Cancer 9(6), 429-439. 2009.

[7] Tsai, S.Y., Chang, Y., Chen, TL., and Chen, R.M., "Therapeutic concentrations of propofol protects mouse macrophages from nitric oxide-induced cell death and apoptosis" Can J Anaesth 49(5), 477-480. 2002.

[8] Saddoughi, S.A., Song, P.F., and Ogretmen, B., "Roles of bioactive sphingolipids in cancer biology and therapeutics" Subcell Biochem 49, 413 - 440. 2008.

[9] Hobbs, A.J., Higgs, A., and Moncada, S., "Inhibition of nitric oxide synthase as a potential therapeutic target” Annu Rev Pharmacol Toxicol 39, 191-220. 1999.

[10] Marletta, M.A., "Nitric oxide synthase structure and mechanism" J Biol Chem 268(17), 12231-12234. 1993.

[11] Chung, H.T., Pae, H.O., Choi, B.M., Billiar, T.R., and Kim, Y.M., "Nitric oxide as a bioregulator of apoptosis, Biochem" Biophys Res Commun 282(5), 1075-1079. 2001.

[12] Xie, Q.W., Cho, H.J., Calaycay, J., Mumford, R.A., Swiderek, K.M., and Lee, T.D., "Cloning and characterization of inducible nitric oxide synthase from mouse macrophages" Science 256(5054), 225-228. 1992.

[13] Lee, S.J., Lee, S.Y., Ha, H.J., Cha, S.H., Lee, S.K., and Hur, S.J., "Rutin Attenuates lipopolysaccharide-induced nitric oxide production in macrophage cells" J Food Nutr Res 3(3), 202-205. 2015.

[14] Lee, S.J., Kim, Y.S., Hwang, J.W., Kim, E.K., Moon, S.H., Jeon, B.T., Jeon, Y.J., Kim, J.M., and Park, P.J., "Purification and characterization of a novel antioxidative peptide from duck skin by-products that protects liver against oxidative damage" Food Res Int 49, 285-295. 2012. 
[15] Bors, W., and Saran, M., "Radical scavenging by flavonoid antioxidants” Free Radic Res Commun 2(4-6), 289-294. 1987.

[16] Fujimura, Y., Tachibana, H., and Yamada, K., "A tea catechin suppresses the expression of the high-affinity IgE receptor $\mathrm{Fc} \varepsilon$ RI in human basophilic KU812 cells” J Agric Food Chem 49(5), 2527-2531. 2001.

[17] Chow, H.H., Cai, Y., Hakim, I.A., Crowell, J.A., Shahi, F., Brooks, C.A., Dorr, R.T., Hara, Y., and Alberts, D.S., "Pharmacokinetics and safety of green tea polyphenols after multiple-dose administration of epigallocatechin gallate and polyphenon $\mathrm{E}$ in healthy individuals" Clin Cancer Res 9(9), 3312-3319. 2003.

[18] Wu, K.M., Ghantous, H., and Birnkrant, D.B., "Current regulatory toxicology perspectives on the development of herbal medicines to prescription drug products in United States" Food Chem Toxicol 46(8), 2606-2610. 2008.

[19] Lee, S.J., Kim, E.K., Kim, Y.S., Hwang, J.W., Lee, K.H., Choi, D.K., Kang, H., Moon, S.H., Jeon, B.T., and Park, P.J., "Purification and characterization of a nitric oxide inhibitory peptide from Ruditapes philippinarum” Food Chem Toxicol 50(5), 1660-1666. 2012.

[20] Kumazoe, M., Sugihara, K., Tsukamoto, S., Huang, Y., Tsurudome, Y., Takashi, S., Yumi, S., Naoki, U., Shuya, Y., Kim Y.H., Yamadam K., and Tachibana, H., "67-kDa laminin receptor increases cGMP to induce cancer-selective apoptosis" J Clin Invest 132(2), 787-799. 2013. 